American Journal of Environmental Sciences 7 (2): 173-177, 2011

ISSN 1553-345X

(C) 2010 Science Publications

\title{
Determination of Absorbed and Effective Dose from Natural Background Radiation around a Nuclear Research Facility
}

\author{
${ }^{1}$ Muhammad Auwal Musa, ${ }^{2}$ Idris Isa Funtua, \\ ${ }^{3}$ Simon Peter Malam and ${ }^{4}$ Abdullahi Suleiman Arabi \\ ${ }^{1}$ Reactor Engineering Section, \\ ${ }^{2}$ Material Science and Development Section, \\ ${ }^{3}$ Health Physics and Radiation Biophysics Section, \\ ${ }^{4}$ Material Science and Development Section, \\ Centre for Energy Research and Training, \\ Ahmadu Bello University, Zaria, Nigeria
}

\begin{abstract}
Problem statement: This study presents result of outdoor absorbed dose rate and estimated effective dose from the naturally occurring radionuclides ${ }^{232} \mathrm{Th}$ and ${ }^{238} \mathrm{U}$ series ${ }^{40} \mathrm{~K}$, around a Nuclear Research Reactor at the Centre for Energy Research and Training (CERT), Zaria, Nigeria. Approach: A high-resolution in situ $\gamma$-ray spectrometry was used to carry out the study. CERT houses a $30 \mathrm{Kw}$ Research Reactor and other neutron and gamma sources for Research and Training. Results: The values of absorbed dose rate in air for ${ }^{232} \mathrm{Th},{ }^{238} \mathrm{U}_{\text {and }}{ }^{40} \mathrm{~K}$ range from $8.2 \pm 2.5-24.5 \pm 3.6 \mathrm{nGy} \mathrm{h}^{-1}, 1.9 \pm 1.2-4.6$ $\pm 2.5 \mathrm{nGy} \mathrm{h}^{-1}$ and $12.2 \pm 5-38 \pm 6.7 \mathrm{n} \mathrm{Gy} \mathrm{h}^{-1}$ respectively . The estimated total annual effective dose outdoor for the sites range from 27.3-79.9 $\mu \mathrm{Sv} \mathrm{y}^{-1}$.Conclusions: This showed that radiation exposure level for the public is lower than the recommended value of $1 \mathrm{mSv} \mathrm{y}{ }^{-1}$. Hence, the extensive usage of radioactive materials within and around CERT does not appear to have any impact on the radiation burden of the environment.
\end{abstract}

Key words: Absorbed dose rate, effective dose, radiation exposure, Global Positioning System (GPS), Centre for Energy Research and Training (CERT), radioactive materials, Naturally Occurring Radionuclides (NORs), terrestrial radionuclides, natural environmental, energy resolution

\section{INTRODUCTION}

The presence of Naturally Occurring Radionuclides (NORs) in the Earth's crust is well known. More than twenty primordial nuclides have been identified, most of them exceeding the age of the Earth by several orders of magnitude (Kathren, 1998). The process of nucleosynthesis in stars forms the primordial radionuclides (also called terrestrial background radiation). Some of the primordial NORs, including ${ }^{40} \mathrm{~K}$ ${ }^{87} \mathrm{Rb},{ }^{232} \mathrm{Th},{ }^{235} \mathrm{U}$, and ${ }^{238} \mathrm{U}$, have their half-lives roughly in the order of the age of the Earth. Primordial nuclides; ${ }^{232} \mathrm{Th},{ }^{235} \mathrm{U},{ }^{238} \mathrm{U}$ are particularly important.

Gamma radiation from radionuclides, such as ${ }^{40} \mathrm{~K}$ and the ${ }^{232} \mathrm{Th}$ and ${ }^{238} \mathrm{U}$ series and their decay products, represents the main external source of irradiation to the human body. External exposures to gamma radiation outdoors arise from terrestrial radionuclides occurring at trace levels in all rock formations. Therefore, the natural environmental radiation mainly depends on geological and geographical conditions. These have direct effect by modifying the soil composition and natural radioactivity concentration levels; and hence the level of absorbed dose received at a locality. Higher radiation levels are associated with igneous rocks, such as granite and lower levels with sedimentary rocks. There are exceptions, however, as some shale and phosphate rocks have relatively high content of radionuclides.

The great interest expressed worldwide for the study of naturally occurring radiation and environmental radioactivity has led to the performance of extensive research in many countries; such as Cyprus, Syria, Greece and Japan. Such investigations can be useful for both assessment of public dose (Aiman et al., 2010). Furthermore performance of

Corresponding Author: Arabi Suleiman Abdullahi, Material Science and Development Section, Centre for Energy Research and Training, Ahmadu Bello University, Zaria-Nigeria 
epidemiological studies, as well as to keep referencedata records, to ascertain possible changes in the environmental radioactivity due to nuclear, industrial and other human activities. The total amount of radioactivity in an environment should be accurately known and kept to A level as Low AS Reasonably Achievable (ALARA). Both laboratory and in-situ gamma spectroscopy are often used for such studies (Tzortzis et al., 2003; Clouvas et al., 2004; Muhammad et al., 2010; Abel-Ghany, 2010).

Environmental radioactivity monitoring is believed to have commenced between late 1959 and early 1960s (Olomo, 1990). Some specific localized studies on radioactivity assessment in Nigerian environment include; radionuclide content of some building materials used in Nigerian dwellings, baseline studies of terrestrial outdoor gamma dose rates levels in Nigeria (Farai and Jibiri, 2000), exposure level around industrial area (Mokobia and logun, 2003; Funtua and Elegba, 2005).

The principal aim of this study is to develop a systematic procedure using high-resolution portable gamma spectrometry system, primarily for assessment and monitoring, of absorbed dose rates and effective dose in air, in the vicinity of nuclear facility. The present work has been conducted in the Centre for Energy Research and Training (CERT), Zaria, Nigeria and some selected settlements around the facility. CERT is a nuclear energy (radiation) based research centre, thus, dealing with substantial quantities of artificial radioactive materials, such as a nuclear research reactor code named Nigeria Research Reactor1 NIRR-1; Am-Be isotopic neutron source, neutron generator among others.

\section{MATERIALS AND METHODS}

Gamma spectrometry system: This is a stand-alone high-resolution spectroscopic system used for the insitu measurement of the emitted gamma rays in the energy range between $50 \mathrm{keV}$ and $3000 \mathrm{keV}$. The system consists of a high-purity germanium (HPGe) detector, EG and $\mathrm{G} \mathrm{ORTEC}^{\circledR}$, coaxial cylinder of crystal length of $46.8 \mathrm{~mm}$ and diameter $55.0 \mathrm{~mm}$, with an efficiency of $23.5 \%$ relative to a $7.6 \times 7.6 \mathrm{~cm}^{2} \mathrm{NaI}(\mathrm{Tl})$ crystal. In addition, energy resolution (FWHM) of 2.0 $\mathrm{keV}$ was achieved, all for a ${ }^{60} \mathrm{Co}$ emission point source at $25 \mathrm{~cm}$ for $1.33 \mathrm{MeV}$. This type of detector can sustain warm up when not in use, which is a convenient feature during extended field trips. The detector was mounted on a portable (hand-held) 10 litres liquid nitrogen dewar that features an all attitude capability. Liquid nitrogen was used for cooling the detector during operation. After filling the portable dewar with liquid nitrogen, it requires a 6 hour cool-down time before becoming operational with $24 \mathrm{~h}$ nominal holding time. The detector assembly was mounted on a $1 \mathrm{~m}$ tripod with the crystal end cap facing down towards the ground. This orientation maximizes the flux that will be intercepted and registered by the detector. The detector unit was connected to a battery powered EG and $G$ ORTEC $^{\circledR}$ "Normad Plus" portable computer based spectroscopy system. High voltage and preamplifier power were supplied to the detector by the system. Advanced Multi-Channel Analyzer (MCA) emulsion software (MAEASTRO-32) was used for data acquisition, storage display and analysis of the acquired gamma-spectra.

Field measurement and analysis: The study site is located at $007^{\circ} 38.523^{\prime}-007^{\circ} 40.822 \mathrm{E}$ and $11^{\circ} 07.83^{\prime}-$ $11^{\circ} 09.790^{\prime} \mathrm{N}$ within the Zaria sheet 102 . The number of monitoring points (MPs) includes; seven locations within the Centre for Energy Research and Training (CERT), Ahmadu Bello University, Zaria and three other locations at selected settlements around CERT within $2 \mathrm{Km}$ radius. The chosen sites were undisturbed with little or no surface features and modest vegetation. These sites were marked-out using Global Positioning System (GPS).

The field measurement of terrestrial gamma radiation was based on the assumption that there exist laterally uniform distribution of natural radionuclides in the environment and that the vertical contribution from the soil is limited to the first horizon $(\approx 10-30 \mathrm{~cm})$. Measurements were performed over flat terrain, which allows source geometry to be represented as an infinite half-space; that is $2 \pi$ geometry in terms of solid angle subtended by the source.

Measurements of spectra in the field were made for a period of 5000s. However, series of random short readings of about $600 \mathrm{~s}$ were first taken, to ensure that, there is approximate uniformity, consequently, the desired counting statistics. The measuring system was routinely checked with ${ }^{137} \mathrm{Cs}$ and ${ }^{60} \mathrm{Co}$ standard sources. Based on two-point energy calibration as set for the operation, prominent peaks were identified and the appropriate regions of interest were set up. The set energy bands define the peaks where the left and right channel markers are representative of the compton continuum. Detector's specific calibration factors (measured efficiency) determined in an earlier experiment, were applied to convert net peak count rate to activity concentration. Only peaks with reasonable gamma-ray emission probabilities were considered.

Since natural radioactive nuclides are assumed to be uniformly distributed in the ground, the dose rates $\left(\mathrm{nGy} \mathrm{h}^{-1}\right.$ ) at $\sim 1 \mathrm{~m}$ above the ground were calculated by the following formula: 
Am. J. Environ. Sci., 7 (2): 173-177, 2011

$\mathrm{D}=\mathrm{A}_{\mathrm{E}} \times \mathrm{C}_{\mathrm{F}}$

Where:

$A_{E}=$ The activity concentration measured in $\mathrm{Bq} \mathrm{Kg}{ }^{-1}$, $\mathrm{C}_{\mathrm{F}}=$ The conversion factor (absorbed dose rate in air per unit activity per unit of soil mass, in units of $\mathrm{nGyh}^{-1}$ per Bq Kg${ }^{-1}$ )

In the present study, the considered Dose Rate Conversion Factors (DRCF) for the ${ }^{232} \mathrm{Th}$ and ${ }^{238} \mathrm{U}$ series and ${ }^{40} \mathrm{~K}$ in the dose rate calculations were those determined by Saito et al. (1995) which had been used extensively for all similar calculations in the UNSCEAR (2000) report. They were multiplied by the measured activity concentration in order to deduce the dose rate due to the entire series. It should be pointed out here that, using this calculation, the dose rate for the ${ }^{232} \mathrm{Th}$ and ${ }^{238} \mathrm{U}$ series is the average of the respective radiological concentrations multiplied by the conversion factors corresponding to each series. The total dose rate for each of the measured samples is the sum of the dose rate contributed by both series of ${ }^{232} \mathrm{Th}$ and ${ }^{238} \mathrm{U}$ and by ${ }^{40} \mathrm{~K}$.

Finally, the effective doses were estimated using Eq. 2. The effective dose outdoor $\mathrm{H}_{\mathrm{E}}$ in unit of $\mathrm{Sv} \mathrm{y}^{-1}$ is given by:

$\mathrm{H}_{\mathrm{E}}=\mathrm{DTF}$

Where:

$\mathrm{D}=$ The calculated dose rate $\left(\mathrm{nGy} \mathrm{h}^{-1}\right) \times(24 \mathrm{~h}$ $\times 365.25 \mathrm{~d}$ )

$\mathrm{T}=$ The occupancy factor $(0.2)$

$\mathrm{F}=$ Conversion coefficient $\left(0.7 \mathrm{~Sv} \mathrm{~Gy}^{-1} \times 10^{-3}\right)$

Taking into account the conversion coefficient from absorbed dose in air to effective dose and the outdoor occupancy factor, a value of $0.7 \mathrm{~Sv} \mathrm{~Gy}{ }^{-1}$ was used for the conversion coefficient from absorbed dose in air to effective dose received by adults and 0.2 for the outdoor occupancy factor UNSCEAR (2000) report.

\section{RESULTS AND DISCUSSION}

The measured absorbed gamma dose rates in air at $1 \mathrm{~m}$ above ground level due to activity concentrations of ${ }^{232} \mathrm{Th}$ and ${ }^{238} \mathrm{U}$ series and ${ }^{40} \mathrm{~K}$ are presented in Table 1. These values range from $8-25 \mathrm{nGy} \mathrm{h}^{-1}, 2-5$ $n G y h^{-1}, 12-38$ nGy h$^{-1}$ respectively. The total absorbed dose rates range from 22-65. $\mathrm{nGy} \mathrm{h}^{-1}$ with a mean of $46.2 \pm 12.5 \mathrm{nGy} \mathrm{h}^{-1}$. According to UNSCEAR (2000),

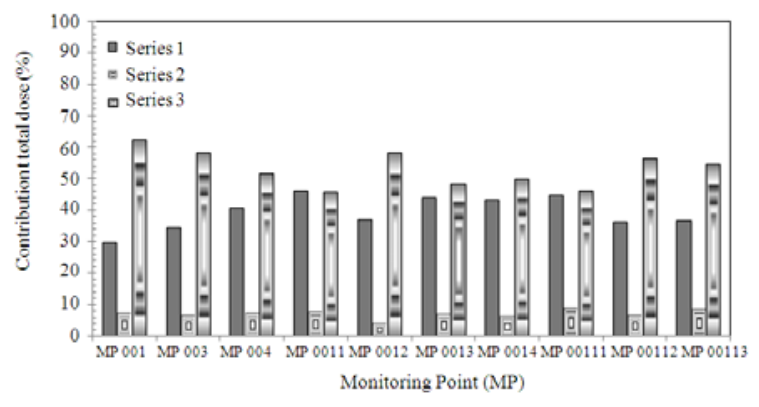

Fig. 1: ${ }^{232} \mathrm{Th},{ }^{238} \mathrm{U},{ }^{40} \mathrm{~K}$, percentage contribution to the total dose rate in air outdoor for the ten monitoring points

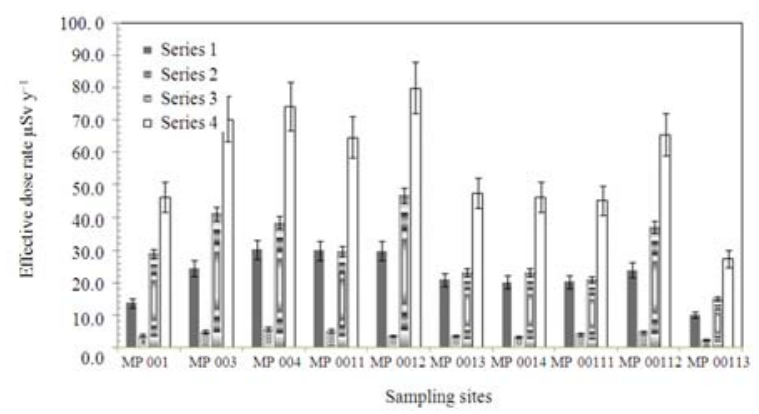

Fig. 2: Estimated effective dose rate due to ${ }^{238} \mathrm{Th},{ }^{238} \mathrm{U}$,

${ }^{40} \mathrm{~K}$, the error bar represent the uncertainty

The corresponding worldwide average values range from 18-93 $\mathrm{nGy} \mathrm{h}^{-1}$ and the population-weighted values gave an average absorbed dose rate in air outdoors from terrestrial gamma radiation as $60 \mathrm{nGy} \mathrm{h}^{-1}$. This shows that the mean value obtained by this study is less than population-weighted worldwide average.

Of all the locations MP004 and MP011 appear to have the highest dose rate due to ${ }^{232} \mathrm{Th}$, also MP004 exhibits the highest dose rate of ${ }^{238} \mathrm{U}$, while the highest dose rate of $38 \mathrm{nGy} \mathrm{h}{ }^{-1}$ due to ${ }^{40} \mathrm{~K}$ was recorded at MP012.The contributions in percent of ${ }^{232} \mathrm{Th}$ and ${ }^{238} \mathrm{U}$ series and ${ }^{40} \mathrm{~K}$ at each measurement location are presented in Fig. 1. These contributions to absorbed gamma dose rate of the ${ }^{232} \mathrm{Th}$ and ${ }^{238} \mathrm{U}$ series and ${ }^{40} \mathrm{~K}$ range from $29.8 \%$ at MP001 to $46.3 \%$ at MP011, $4.3 \%$ at MP012 to $9.0 \%$ at MP111 and $45.9 \%$ at MP011 to $62.5 \%$ at MP001 with a mean contributions of $39.3,7.3$ and $57.3 \%$ respectively.

The estimated outdoor effective dose according to equation 2 for the sites as presented in Fig. 2 range from 27.3-79.9 $\mu \mathrm{Sv} \mathrm{y}^{-1}$ with a mean of $0.57 \mathrm{mSv} \mathrm{y}^{-1}$ which is significantly lower than the worldwide average exposure of $0.7 \mathrm{mSv} \mathrm{y}^{-1}$ (UNSCAER, 2000). 
Am. J. Environ. Sci., 7 (2): 173-177, 2011

Table 1: Global Positioning System (GPS) coordinates and the measured absorbed gamma dose rates in air at $1 \mathrm{~m}$ above ground level due to activity concentrations of ${ }^{232} \mathrm{Th}$ and ${ }^{238} \mathrm{U}$ series and ${ }^{40} \mathrm{~K}$ for the monitoring points

\begin{tabular}{|c|c|c|c|c|c|c|}
\hline \multirow[b]{2}{*}{ Site ID } & \multicolumn{2}{|l|}{ Location } & \multirow{2}{*}{$\begin{array}{l}{ }^{232} \text { Th series } \\
\left(\text { nGy. } \mathrm{h}^{-1}\right)\end{array}$} & \multirow{2}{*}{$\begin{array}{l}{ }^{238} \mathrm{U} \text { series } \\
\left(\mathrm{nGy} \cdot \mathrm{h}^{-1}\right)\end{array}$} & \multirow{2}{*}{$\begin{array}{l}{ }^{40} \mathrm{~K} \\
\left(\mathrm{nGy} \cdot \mathrm{h}^{-1}\right)\end{array}$} & \multirow{2}{*}{$\begin{array}{l}\text { Total dose rates } \\
\left(\text { nGy. } \mathrm{h}^{-1}\right)\end{array}$} \\
\hline & Latitude & Longitude & & & & \\
\hline MP001 & $11^{\circ} 08.439^{\prime} \mathrm{N}$ & $07^{\circ} 39.840^{\prime} \mathrm{E}$ & $11.2 \pm 2.9$ & $2.9 \pm 0.7$ & $23.5 \pm 6.0$ & $37.6 \pm 9.6$ \\
\hline MP003 & $11^{\circ} 08.476^{\prime} \mathrm{N}$ & $07^{\circ} 39.901^{\prime} \mathrm{E}$ & $19.8 \pm 2.8$ & $3.9 \pm 2.1$ & $33.5 \pm 5.3$ & $57.2 \pm 10.2$ \\
\hline MP004 & $11^{\circ} 08.497^{\prime} \mathrm{N}$ & $07^{\circ} 39.851^{\prime} \mathrm{E}$ & $24.5 \pm 3.6$ & $4.6 \pm 2.5$ & $31.3 \pm 9.4$ & $60.4 \pm 15.5$ \\
\hline MP011 & $11^{\circ} 08.415^{\prime} \mathrm{N}$ & $07^{\circ} 39.776^{\prime} \mathrm{E}$ & $24.4 \pm 5.5$ & $4.1 \pm 2.0$ & $24.2 \pm 7.0$ & $52.7 \pm 14.5$ \\
\hline MP012 & $11^{\circ} 08.358^{\prime} \mathrm{N}$ & $07^{\circ} 39.912^{\prime} \mathrm{E}$ & $24.2 \pm 4.6$ & $2.8 \pm 1.1$ & $38 \pm 6.7 .0$ & $65.1 \pm 12.4$ \\
\hline MP013 & $11^{\circ} 08.505^{\prime} \mathrm{N}$ & $07^{\circ} 39.963^{\prime} \mathrm{E}$ & $17 \pm 5.7$ & $2.8 \pm 0.7$ & $18.8 \pm 8.1$ & $38.6 \pm 14.6$ \\
\hline MP014 & $11^{\circ} 08.549^{\prime} \mathrm{N}$ & $07^{\circ} 39.823^{\prime} \mathrm{E}$ & $16.3 \pm 3.8$ & $2.5 \pm 0.8$ & $18.8 \pm 5.3$ & $37.7 \pm 9.9$ \\
\hline MP111 & $11^{\circ} 07.830^{\prime} \mathrm{N}$ & $07^{\circ} 39.447^{\prime} \mathrm{E}$ & $16.4 \pm 4.7$ & $3.3 \pm 1.4$ & $17.1 \pm 7.0$ & $36.8 \pm 13.1$ \\
\hline MP112 & $11^{\circ} 08.205^{\prime} \mathrm{N}$ & $07^{\circ} 40.186^{\prime} \mathrm{E}$ & $19.4 \pm 5.9$ & $3.7 \pm 2.0$ & $30.3 \pm 8.3$ & $53.4 \pm 16.2$ \\
\hline MP113 & $11^{\circ} 08.749^{\prime} \mathrm{N}$ & $07^{\circ} 40.822^{\prime} \mathrm{E}$ & $8.2 \pm 2.5$ & $1.9 \pm 1.2$ & $12.2 \pm 5.0$ & $22.3 \pm 8.7$ \\
\hline
\end{tabular}

Thus, the exposure level for the public is within the recommended value of $1 \mathrm{mSv} \mathrm{y}^{-1}$ IAEA (1996) (Safety Series No. 115-I).The highest and lowest effective doses of 79.9 and $27.3 \mu \mathrm{Sv} \mathrm{y}^{-1}$ were registered at MP012 and MP113.respectively.

\section{CONCLUSION}

In this study portable gamma ray spectroscopy was exploited to develop a systematic procedure for rapid and effective determination of outdoor absorbed and effective dose in a vicinity of nuclear facility. The in situ results obtained by the present work would serve as a baseline data for assessment and operational monitoring of outdoor exposure around Centre for Energy Research and Training (CERT).Values obtained were lower than the population-weighted worldwide average.

\section{ACKNOWLEDGEMENT}

The researchers wish to acknowledge the contributions of the management of CERT and the department of Physics of the Ahmadu Bello University, Zaria for allowing us access some of the facilities utilized in this study.

\section{REFERENCES}

Abel-Ghany, H.A., 2010. Natural activities of ${ }^{238} \mathrm{U}$, ${ }^{232} \mathrm{Th}$ and ${ }^{40} \mathrm{~K}$ in manganese ore. Am. J. Environ. Sci., 6: 90-94. DOI: 10.3844/ajessp.2010.90.94

Aiman, I., M.D. Norashidah, M.Z. Jamaludin and B. Nagaletchumi, 2010. Mobile phone base station radiation study for addressing public concern. Am. J. Eng. Applied Sci., 3:117-120. DOI: 10.3844/ajeassp.2010.117.120
Clouvas, A., S. Xanthos and M. Antonopoulos-Domis, 2004. Radiological maps of outdoor and indoor gamma dose rates in Greek Urban areas obtained by in situ gamma spectrometry. Radiat. Prot. Dosim., 112: 267-275. DOI: 10.1093/rpd/nch395

Farai, I.P. and N.N. Jibiri, 2000. Baseline studies of terrestrial outdoor gamma dose rate levels in Nigeria. Radiat. Prot. Dosim, 88: 247-254. http://rpd.oxfordjournals.org/content/88/3/247.short

Funtua, I.I. and S.B. Elegba, 2005. Radiation exposure from high-level radiation area and related mining and processing activities of Jos Plateau, central Nigeria. Int. Congress Series, 1276: 401-402. DOI: 10.1016/j.ics.2004.10.006

IAEA, 1996. International Basic Safety Standards for Protection against Ionizing Radiation and for the Safety of Radiation Sources, IAEA, Vienna. http://www-pub.iaea.org/mtcd/publications/pdf/ss115-web/pub996_web-1a.pdf

Kathren, R.L., 1998. NORM sources and their origins. Appl. Radi. Isot., 49: 149-168. PMID: 9451770 http://www.ncbi.nlm.nih.gov/pubmed/9451770

Muhammad, A.M., I.I. Funtua, S.P. Malam and A.S. Arabi, 2010. Distribution of gamma-emitting radionuclides in soils around the Centre for Energy Research and Training (CERT) Ahmadu Bello University, Zaria, Zaria-Nigeria. J. Am. Sci., 6: 995-1001. http://www.jofamericanscience.org/journals/amsci/am0612/

Mokobia, C.E. and F.A. logun, 2003. Background gamma terrestrial dose rate in Nigerian functional coal mines. Radiat. Prot. Dosim., 108: 169-173. DOI: $10.1093 / \mathrm{rpd} / \mathrm{nch} 003$

Olomo, J.B., 1990. The natural radioactivity in some Nigerian foodstuffs. Nucl. Instrum. Meth., 299: 666-669. DOI: 10.1016/0168-9002(90)90866-5 
Am. J. Environ. Sci., 7 (2): 173-177, 2011

Tzortzis, M., H. Tsertos, S. Christofides and G. Christodoulides, 2003. Gamma-ray measurements of naturally occurring radioactive samples from Cyprus characteristic geological rocks. Radiat. Measur., 37 221-229.

http://arxiv.org/abs/physics/0212099 